\title{
Seismic attenuation beneath Kanto, Japan: evidence for high attenuation in the serpentinized subducting mantle
}

\author{
Junichi Nakajima
}

\begin{abstract}
The three-dimensional (3-D) $P$-wave attenuation $\left(Q_{p}^{-1}\right)$ structure beneath Kanto, Japan, is estimated by using a large number of waveform data. Corner frequencies of earthquakes are initially calculated from spectral ratios of S-coda waves, followed by an inversion to simultaneously determine attenuation terms and frequency-dependent site amplification factors. The attenuation terms are then inverted for estimation of the $3-D Q_{p}^{-1}$ structure. The obtained results show that seismic attenuation is highly heterogeneous, and pronounced high-attenuation areas are located in the continental lower crust and mantle of the Philippine Sea slab. Seismic activity is very low in the high-attenuation lower crust, which is most likely attributable to ductile deformation facilitated by fluids supplied from the underlying Philippine Sea slab. The high-attenuation area in the Philippine Sea slab represents the serpentinized mantle, and two $M \sim 7$ earthquakes are documented to have occurred along the western boundary of this area. Interplate earthquakes on the Pacific slab are absent in areas overlain by the serpentinized Philippine Sea slab, which is likely due to the low viscosity of serpentine promoting continuous ductile deformation rather than brittle failures along the plate boundary.
\end{abstract}

Keywords: Serpentine; Intermediate-depth earthquakes; Interplate earthquakes; Fluids; Ductile deformation; Dehydration

\section{Background}

Beneath the Kanto district of Japan, which contains the Tokyo metropolitan area, the Philippine Sea plate is subducting under the continental plate along the Sagami trough, and the Pacific plate is subducting below the Philippine Sea and continental plates along the Japan trench (Figure 1a). The dual subduction of these oceanic plates has resulted in a highly complex tectonic scenario beneath Kanto. Our understanding of seismotectonics in this region has vastly improved in the last decade following comprehensive studies on the geometries of the subducting Pacific and Philippine Sea plates (e.g., Sato et al. 2005; Hirose et al. 2008; Nakajima et al. 2009; Uchida et al. 2010), the distribution of small repeating earthquakes (e.g., Kimura et al. 2006; Uchida et al. 2009), seismic velocity structures (e.g., Matsubara et al. 2005; Wu et al. 2007), and stress regimes derived from focal mechanism of earthquakes (e.g., Hori 2006; Nakajima et al. 2011).

Correspondence: nakajima@aob.gp.tohoku.ac.jp

Research Center for Prediction of Earthquakes and Volcanic Eruptions, Graduate School of Science, Tohoku University, Sendai 980-8578, Japan
One of the most important findings was a low-velocity and high-Vp/Vs mantle of the Philippine Sea slab beneath eastern Kanto, which is interpreted as being the serpentinized mantle (Figure 1b) (Nakajima et al. 2009). Nakajima and Hasegawa (2010) emphasized the important role of the western boundary of the serpentinized mantle on seismogenesis beneath Kanto and suggested that the western unmetamorphosed mantle moves 0.5 to $1 \mathrm{~cm} /$ year relative to the eastern serpentinized mantle.

Seismic attenuation provides additional insights into seismogenesis and plays a crucial role in the estimation of strong surface motions, but there are few studies on three-dimensional (3-D) seismic attenuation beneath Kanto. A pioneering work by Sekiguchi (1991) imaged the subducting Philippine Sea slab as a marked low-attenuation area, and Nakamura et al. (2006) revealed the existence of a pronounced E-W trending high-attenuation area at depths of 20 to $60 \mathrm{~km}$. However, we still do not have enough information on seismic attenuation compared to seismic velocity. Therefore, precisely estimating seismic attenuation is of considerable importance to understand 

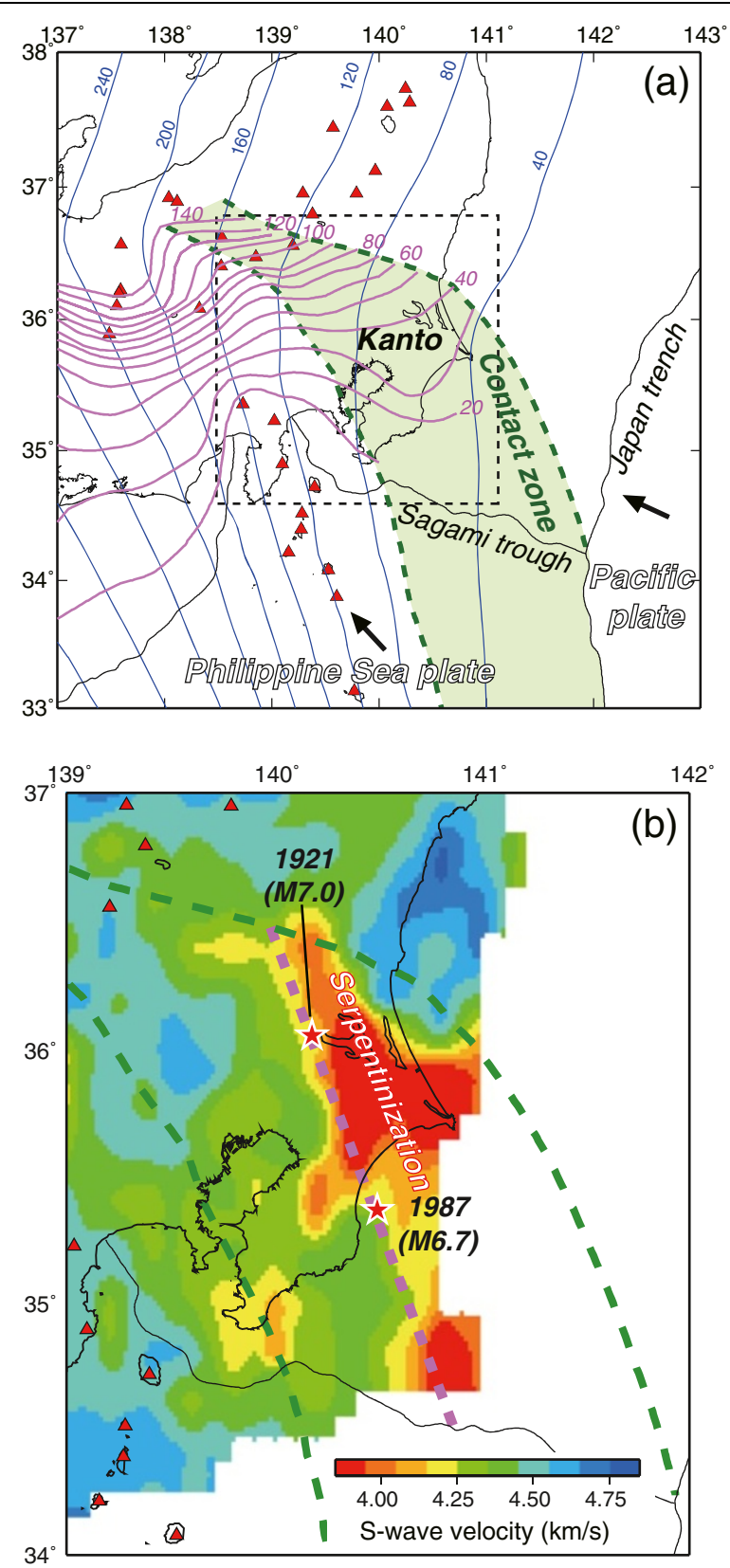

Figure 1 Study area and S-wave velocity image in the Philippine Sea slab. (a) The tectonic setting of central Japan. Red triangles denote active volcanoes. Iso-depth contours of the Pacific and Philippine Sea slabs (Nakajima and Hasegawa 2007; Hirose et al. 2008; Nakajima et al. 2009) are shown by blue and pink curves, respectively. Green shading represents an area where the upper surface of the Pacific slab is in contact with the lower surface of the Philippine Sea slab, termed the slab contact zone (Nakajima et al. 2009; Uchida et al. 2009). Arrows represent the directions of motion of the Philippine Sea and Pacific plates. The extent of the studied area is marked by a dashed rectangle. (b) Map showing S-wave velocity distribution along a curved surface located $10 \mathrm{~km}$ above the Pacific slab (after Nakajima et al. 2009). Red stars denote two earthquakes that occurred in the Philippine Sea slab in 1921 (M7.0) and 1987 (M6.7). A dashed pink line represents the western boundary of the serpentinized mantle of the Philippine Sea slab.

the complicated structure and mechanical interactions between the two subducting slabs. In this study, the 3D $P$-wave attenuation $\left(Q_{p}^{-1}\right)$ structure is estimated by using a large number of high-quality waveform data recorded at a nationwide seismograph network in Japan. The results are then discussed with reference to seismotectonics beneath Kanto.

\section{Methods}

Corner frequency, attenuation term, and site response

The three-step approach developed by Nakajima et al. (2013) was applied to estimate 3-D $Q_{p}^{-1}$ structure, which can minimize potential tradeoffs among unknown parameters to be solved, in addition to attenuation terms $\left(t^{*}\right)$ along a ray path. Firstly, corner 

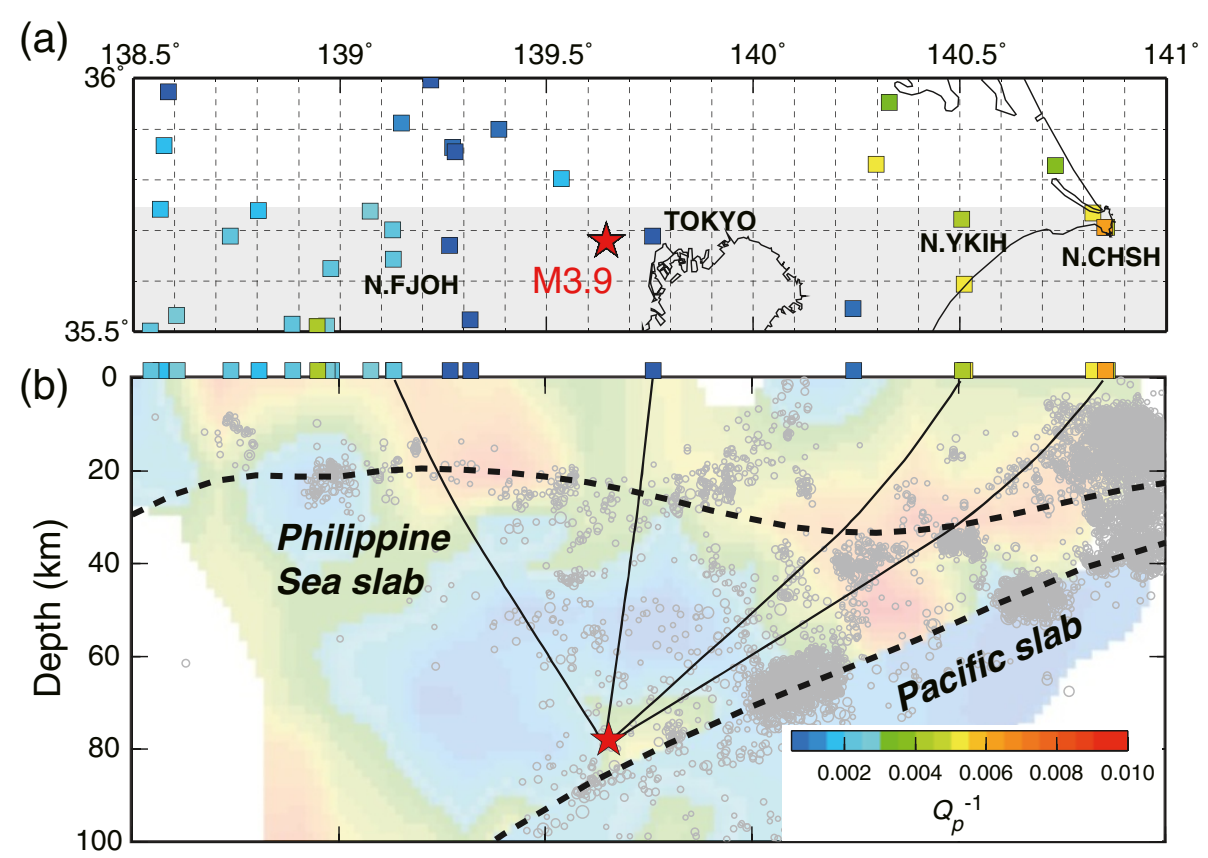

(c)
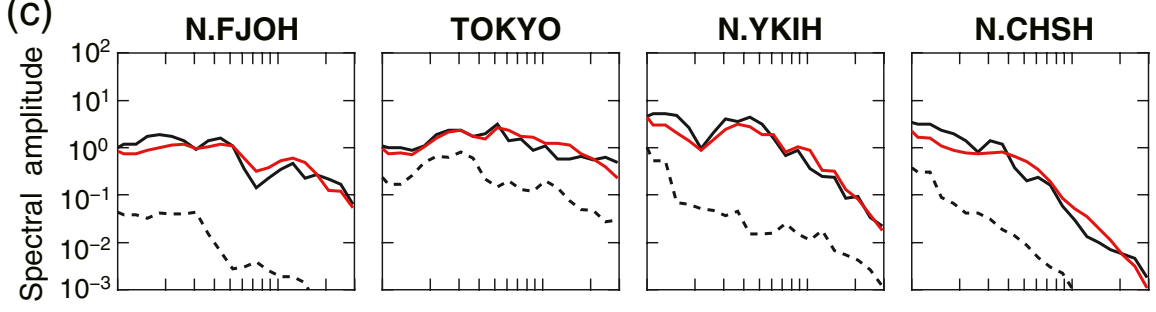

(d)
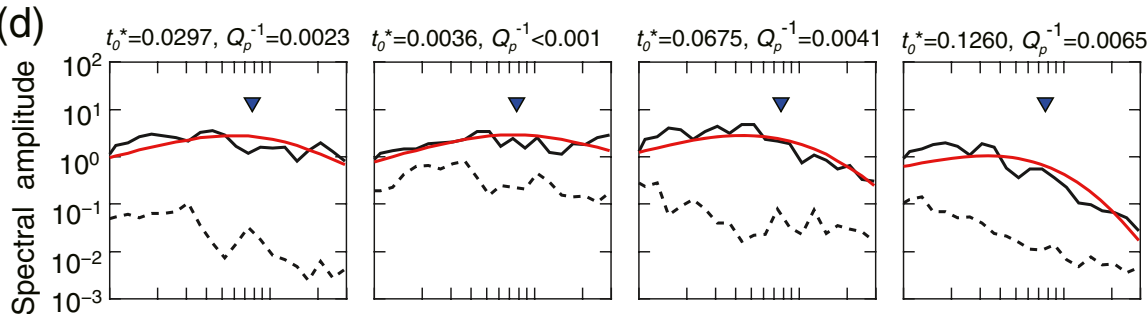

(e)
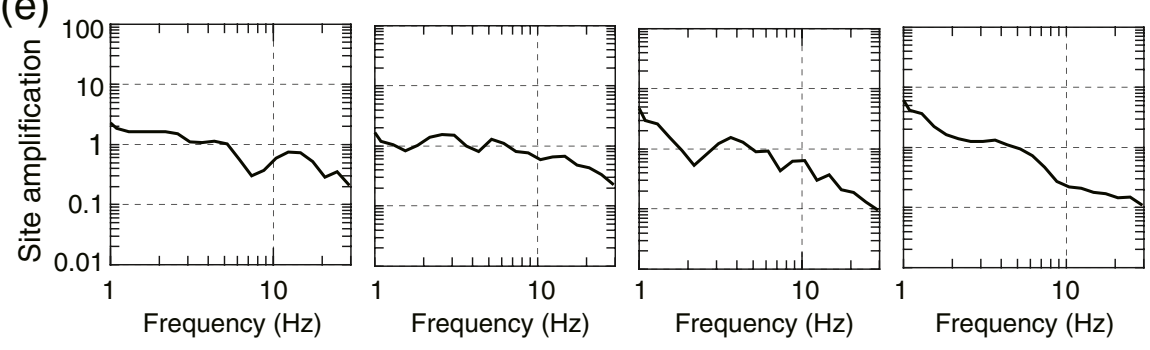

Figure 2 (See legend on next page.) 
(See figure on previous page.)

Figure 2 Examples of results obtained for an earthquake (M3.9) with a depth of $\mathbf{7 9} \mathbf{~ k m}$. (a) Map showing path-average $Q_{p}^{-1}$ plotted at station locations (colored squares). Colors represent $Q_{p}^{-1}$ values and color scales are shown in (b). The epicenter of the M3.9 earthquake is shown by a red star. (b) Vertical cross section of the $Q_{p}^{-1}$ model obtained in this study along latitude of $35.6^{\circ} \mathrm{N}$. Stations and earthquakes located in the gray band in (a) are shown by colored squares and gray circles, respectively. Black lines denote ray paths from the M3.9 earthquake (red star) to four stations (N.CHSH, N.YKIH, TOKYO, and N.FJOH) that are calculated with a 3-D P-wave velocity model (Nakajima et al. 2009). Dashed lines denote the upper surfaces of the Philippine Sea and Pacific slabs (Hirose et al. 2008; Nakajima et al. 2009). (c) Spectral amplitudes for $P$ waves (black line) and noises (dashed line) observed at the four stations. The names of stations are shown above each panel. A red line represents the theoretical spectral amplitude calculated with $t_{0}{ }^{*}$, site-amplification factors, and the $\omega^{2}$ source model. (d) Spectral amplitudes for $P$ waves (black line) and noises (dashed line) corrected for site-amplification factors. A red line represents the theoretical spectral amplitude calculated with $t_{0}{ }^{*}$ and the $\omega^{2}$ source model. Inverted triangles denote the $P$-wave corner frequency of the M3.9 earthquake. Values of $t_{0}^{*}$ and path-average $Q_{p}^{-1}$ are shown above each panel. (e) Site amplification factors estimated for the four stations.

frequencies $\left(f_{c}\right)$ of earthquakes were estimated from spectral ratios of $S$-coda waves, and then a joint inversion was performed in order to determine attenuation terms and frequency-dependent site-amplification factors. Finally, the set of $t^{*}$ was inverted for the 3-D $Q_{p}^{-1}$ structure. The same criteria for waveform analysis and parameter selections given in Nakajima et al. (2013) were adopted for this study, and the outline of the analysis is described in the following paragraphs.

Velocity waveforms were collected for 336 earthquakes with focal depths $(H)$ of less than $30 \mathrm{~km}$ and 2,621 earthquakes with $H \geq 30 \mathrm{~km}$, all of which occurred from January 2003 to October 2013. Magnitudes of these earthquakes ranged from 2.5 to 5.0. Spectral amplitudes of the transverse component were calculated for $S$-coda waves, with a time window of $10 \mathrm{~s}$ taken at twice the theoretical $S$-wave travel time for the 1-D seismic velocity model (Hasegawa et al. 1978). Spectral ratios were calculated at common stations for available earthquake pairs that had a magnitude difference of $\geq 0.5$, and the spectral ratios were subsequently stacked. Then, an $\omega^{2}$ source model (Brune 1970) was fitted to the stacked spectral ratio in the 1 - to $32-\mathrm{Hz}$ frequency range, and values of $f_{c}$ for the earthquake pair were estimated. As a result, $f_{c}$ for 1,915 earthquakes were determined.

$P$-wave and noise spectral amplitudes were subsequently calculated from the vertical component with a window length of $2.56 \mathrm{~s}$ after and before the onset of $P$-wave arrival, respectively. We assumed a frequency-dependent attenuation term, $t^{*}(f)$, as $t^{*}(f)=t_{0}^{*} f^{-\alpha}$, where $t_{0}^{*}$ is the attenuation term at $1 \mathrm{~Hz}$ (e.g., Stachnik et al. 2004). A frequency-dependent term, $\alpha$, was estimated by the method of Stachnik et al. (2004), yielding the optimal range of 0.2 to 0.3 . The most relevant $\alpha$ for the mantle, 0.27 (e.g., Jackson et al. 2002), lies in this range, and therefore, $\alpha$ of 0.27 was adopted as the frequency-dependent factor. Observation equations were constructed as a set of equations for many earthquakes at one station and a joint inversion was carried out for $t_{0} *$, frequencydependent site-amplification factors, and an offset that controls the level of spectra.
Figure 2a shows path-average $Q_{p}^{-1}$ plotted on each station, which were calculated from $t_{0} *$ for an earthquake (M3.9) at a depth of $79 \mathrm{~km}$. Stations in the western part of the study area show low attenuation, whereas stations in the eastern part show moderate to high attenuation. Ray paths from the earthquake to four stations, N.CHSH, N. YKIH, TOKYO, and N.FJOH, are shown in Figure 2b. Observed spectral amplitudes (black curve) at the four stations are explained well by theoretical spectral amplitudes (red curve) calculated with the estimated $t_{0}^{*}$, site-amplification factors, and the $\omega^{2}$ source model (Figure 2c). Observed and theoretical spectral amplitudes that are corrected for siteamplification factors show a rather smooth pattern over the frequency range of interest and are explained by the estimated $t_{0}^{*}$ together with the $\omega^{2}$ source model (Figure $2 \mathrm{~d}$ ).

\section{Tomographic inversion}

The 3-D $Q_{p}^{-1}$ structure was estimated by the inversion of $t_{0}$ * (e.g., Rietbrock 2001). The ray-tracing technique of Zhao et al. (1992) was used to calculate ray paths and travel times for the 3-D P-wave velocity model of Nakajima et al. (2009). The Conrad and Moho discontinuities in the continental plate (Katsumata 2010), and the upper boundary of the subducting Pacific plate (Nakajima et al. 2009) were introduced as velocity discontinuities in the model space. Two 3-D grid nets were set in the model space, and a value of $Q_{p}^{-1}$ for each grid node was estimated. One net covered the crust and mantle in the continental and Philippine Sea plates, with grid nodes spaced at a horizontal interval of $0.1^{\circ}$ and vertical intervals of 10 to $20 \mathrm{~km}$ down to a depth of $200 \mathrm{~km}$. The other net covered the Pacific slab, where grid nodes with a horizontal interval of $0.2^{\circ}$ were set at distances of 5,20 , and $40 \mathrm{~km}$ from the slab surface and orientated subparallel to it. Initial values of 0.0033 were used for $Q_{p}^{-1}$ for the crust and mantle and 0.001 for the Pacific slab.

The distributions of the 1,915 earthquakes and 165 seismograph stations used in this study are shown in Figure 3. A total of $80,644 t_{0}$ * were used in the inversion, and $Q_{p}^{-1}$ values were estimated at grid nodes with more than 100 rays. The optimum damping parameter was 


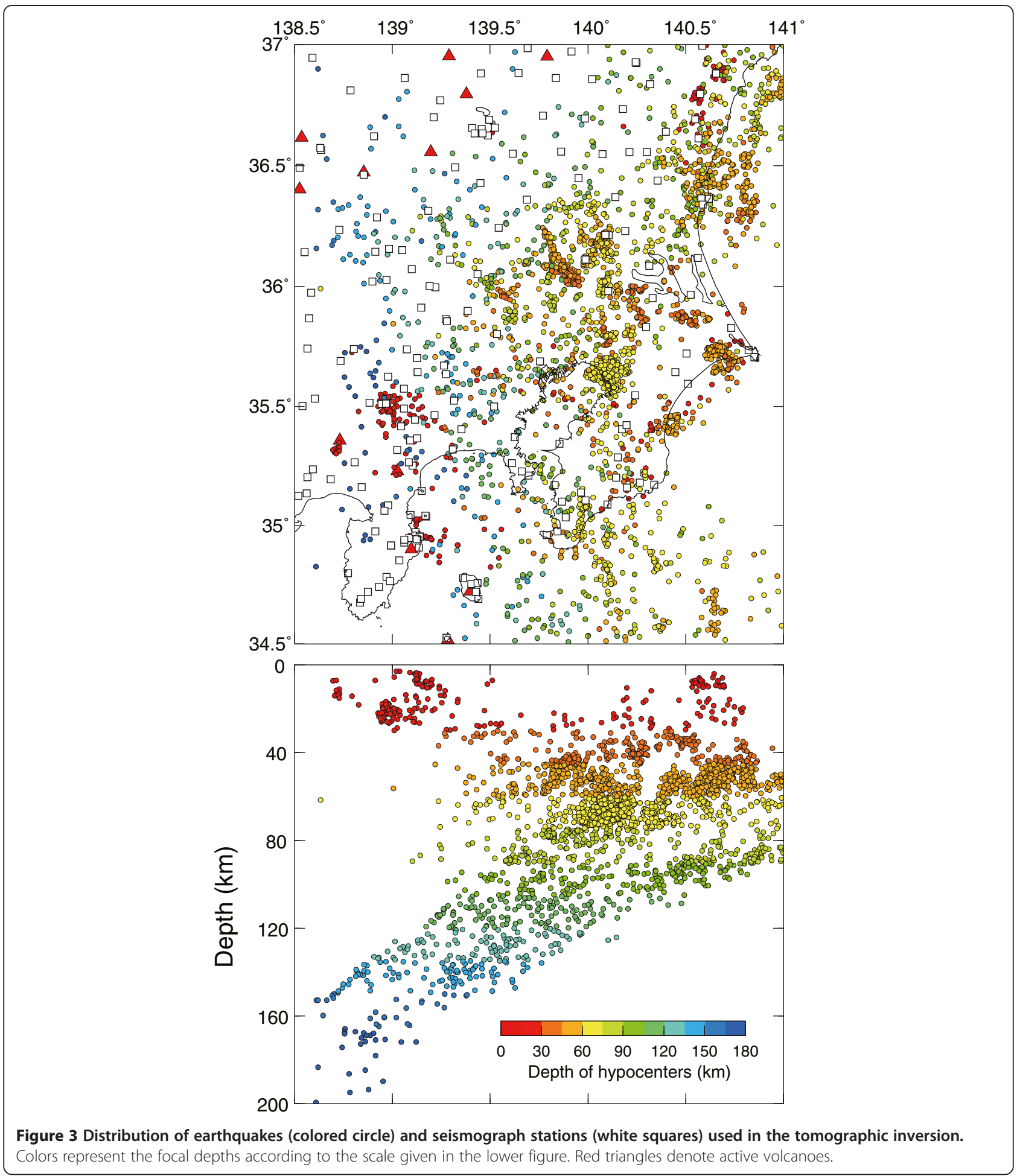

chosen to be 50, based on the tradeoff curve between model variances and data residuals. The final results were obtained after four iterations, and the RMS of $t_{0}{ }^{*}$ residuals was reduced from $0.034 \mathrm{~s}$ in the initial model to $0.020 \mathrm{~s}$ upon optimization.
Checkerboard resolution tests (CRTs) were used to assess the resolution of the obtained images. $Q_{p}^{-1}$ values of 0.007 and 0.001 were assigned alternately to grid nodes with every $0.2^{\circ}$ interval in the horizontal direction and synthetic $t_{0}$ * was calculated with the same source-receiver geometry 


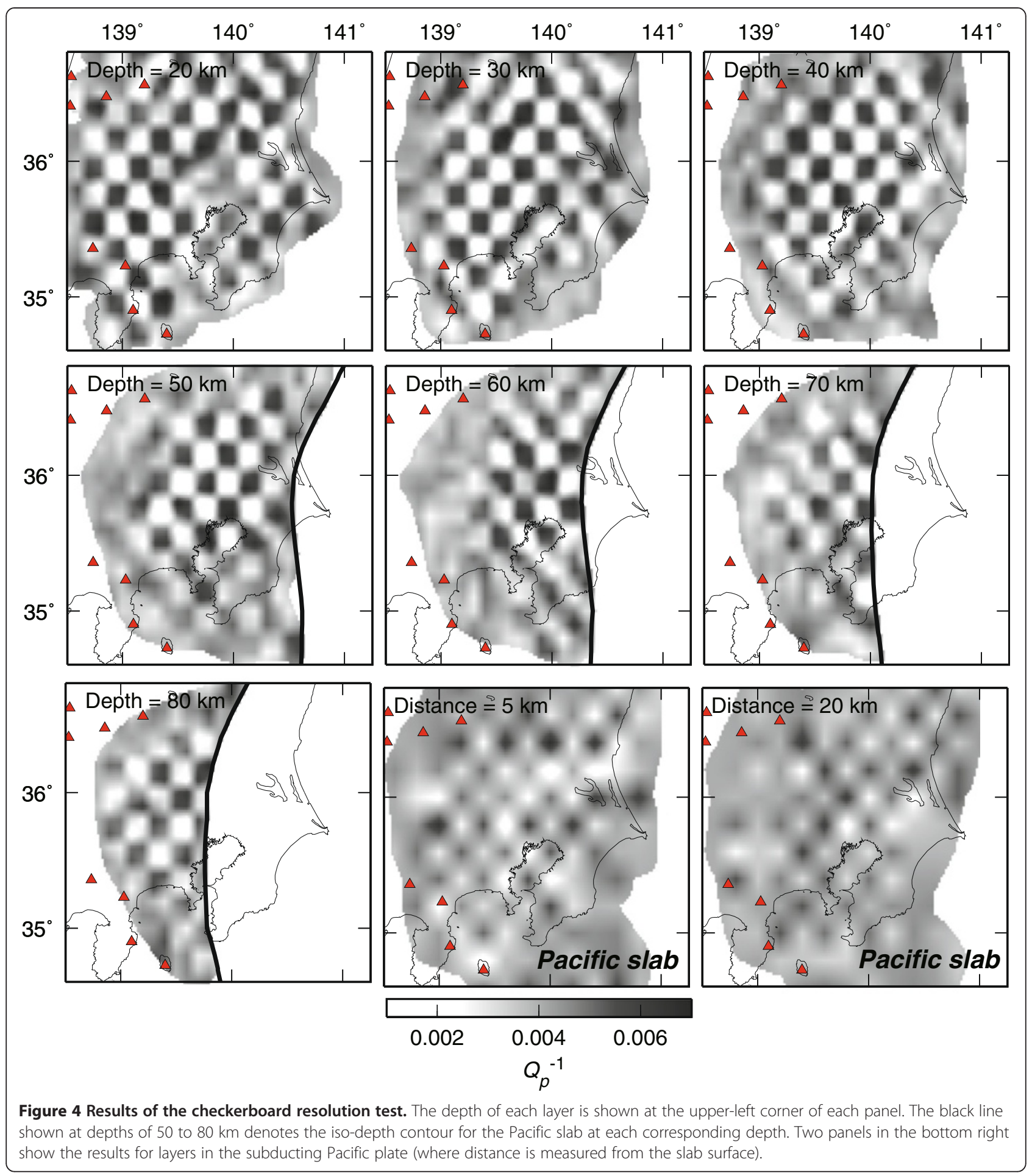

as the observations. Random noises with a standard deviation of $0.01 \mathrm{~s}$ were added to the synthetic data, and the synthetic $t_{0}{ }^{*}$ were inverted to obtain checkerboard images. The results show that checkerboard patterns are recovered well down to a depth of $80 \mathrm{~km}$ (Figure 4), whereas those in the subducting Pacific slab are slightly smeared, probably due to the limited and less-crisscrossed ray coverage. The results of CRTs demonstrate that the data set can resolve 3$\mathrm{D} Q_{p}^{-1}$ structure above the Pacific slab with a spatial resolution of approximately $20 \mathrm{~km}$. 


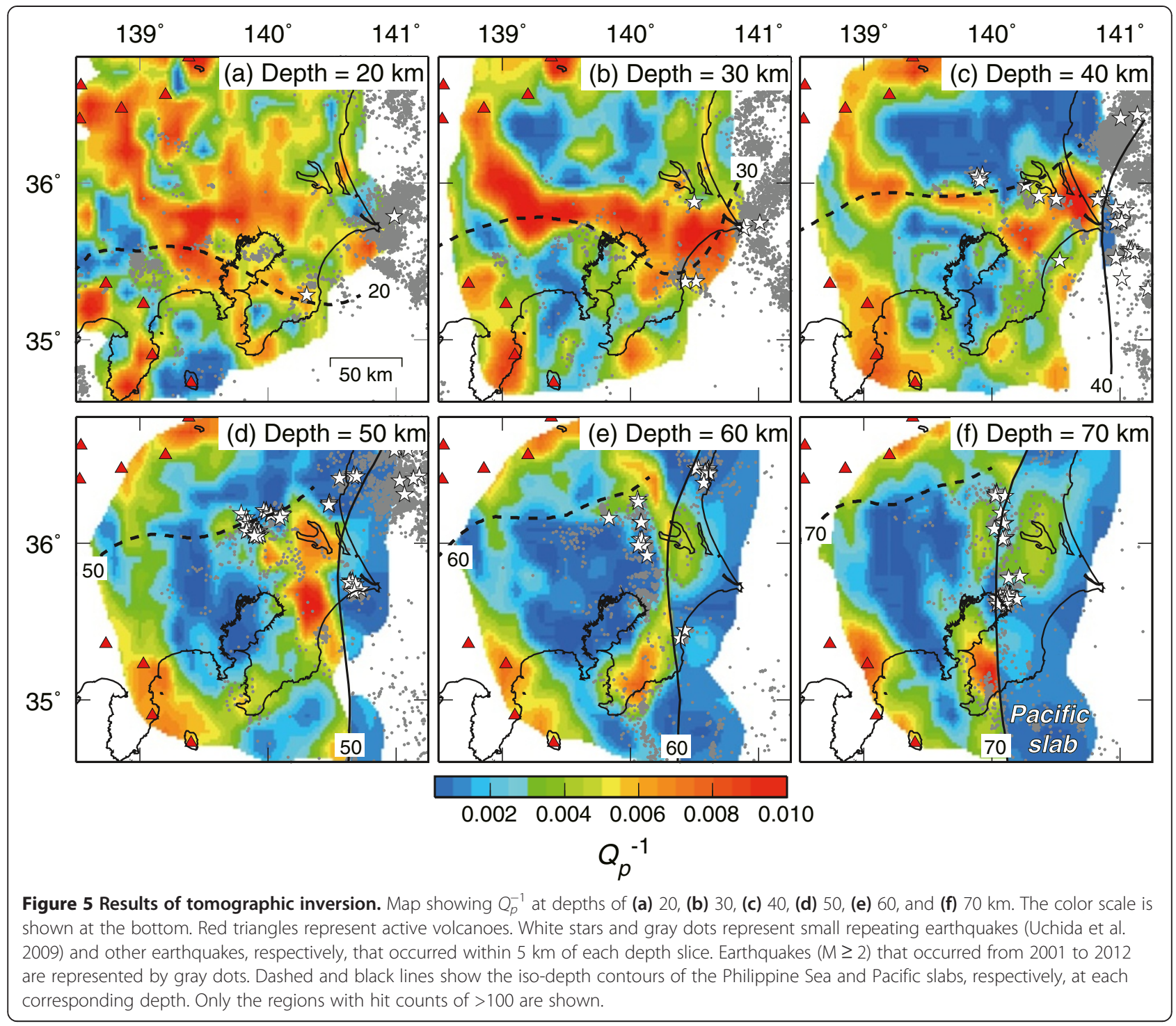

\section{Results}

High-attenuation $\left(Q_{p}^{-1}>0.005\right)$ areas are distributed over a wide region of Kanto at a depth of $20 \mathrm{~km}$, and a significant E-W trending high-attenuation area is observed along latitudes of 35.5 to $36.0^{\circ} \mathrm{N}$ at depths of 30 and $40 \mathrm{~km}$. This latter high-attenuation area coincides spatially with an area characterized by low velocity and high Vp/Vs (e.g., Kamiya and Kobayashi 2000; Matsubara et al. 2005). When compared with iso-depth contours for the Philippine Sea slab (broken curve in Figure 5), it is evident that the E-W trending highattenuation area occurs within the continental plate at a depth of $30 \mathrm{~km}$, whereas it corresponds to the subducting crust at a depth of $40 \mathrm{~km}$. At a depth of $50 \mathrm{~km}$, a N-S oriented high-attenuation area is imaged in the Philippine Sea slab immediately above the
Pacific slab. This area was also partly observed by Nakamura et al. (2006). Altogether, the Philippine Sea slab is imaged as a low-attenuation zone $\left(Q_{p}^{-1}<0.002\right)$ at depths of 60 and $70 \mathrm{~km}$.

Figure 6 shows that high-attenuation areas observed in this study coincide spatially with low-velocity areas. The continental lower crust situated immediately above the Philippine Sea slab shows high attenuation, and high attenuation continues to the surface in some areas (lines $\mathrm{A}$ and E). The continental mantle shows distinct zones of high attenuation beneath volcanic areas along the western limit of lines A-C. Interestingly, a localized high attenuation is observed at the corner of the mantle wedge where no volcanic activity occurs at the surface (lines D and E). Furthermore, high attenuation is imaged in the Philippine Sea slab crust and mantle, the latter 

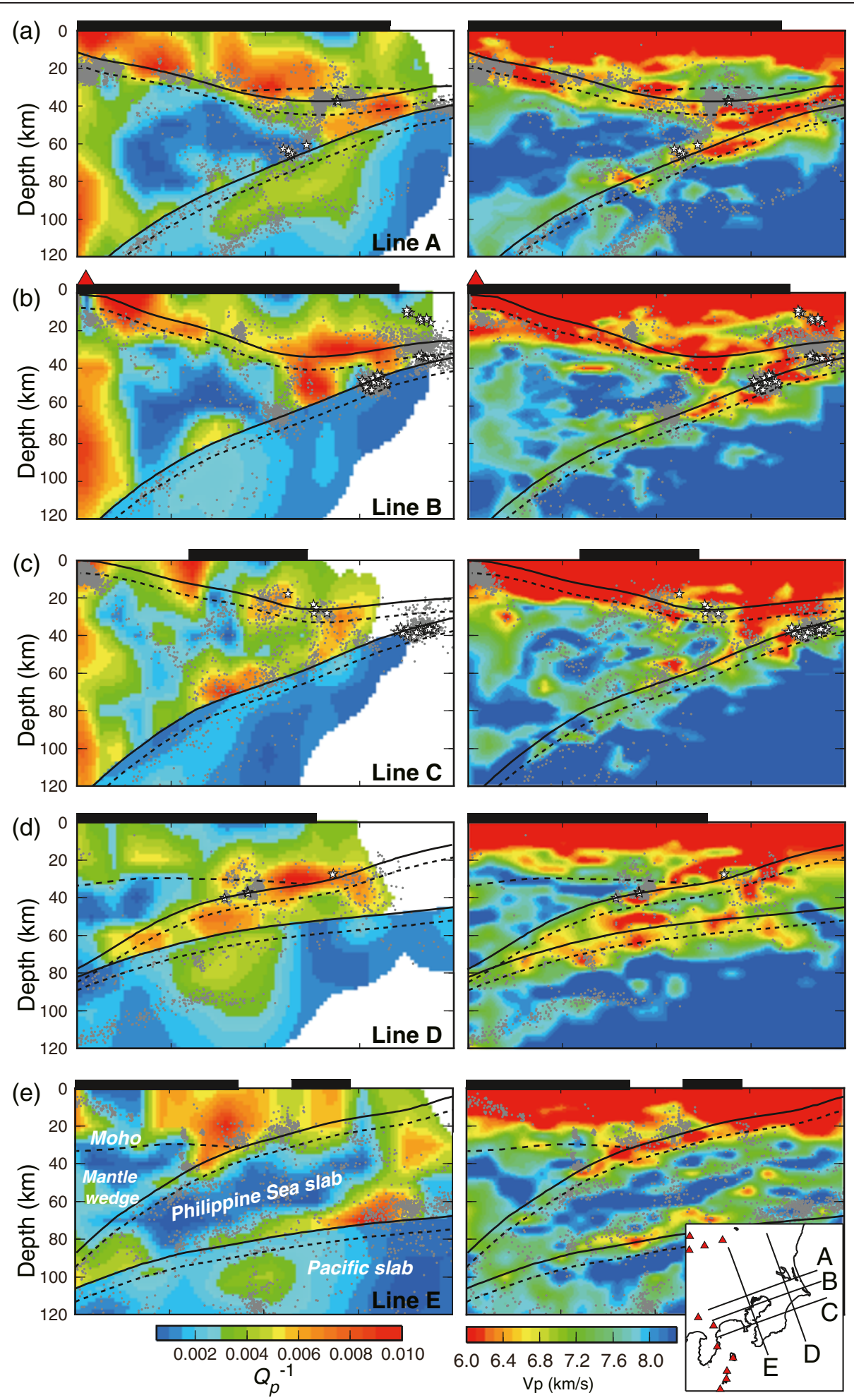

Figure 6 Comparison between (left) $Q_{p}^{-1}$ and (right) $P$-wave velocity. Vertical cross-sections along the lines (a) $A$, (b) $B$, (c) $C$, (d) $D$, and (e) $E$ in the inset map are shown. Solid lines indicate the upper surfaces of the Philippine Sea and Pacific slabs, and dashed lines denote the Moho for the continental plate and Philippine Sea and Pacific slabs. Black bars and red triangles on the top of each panel denote the land area and volcanoes, respectively. White stars and gray dots represent small repeating earthquakes and other earthquakes, respectively, that occurred within $5 \mathrm{~km}$ from each line. Earthquakes $(M \geq 2)$ that occurred from 2001 to 2012 are represented by gray dots. The $P$-wave velocity model is reproduced from Nakajima and Hasegawa (2010). 


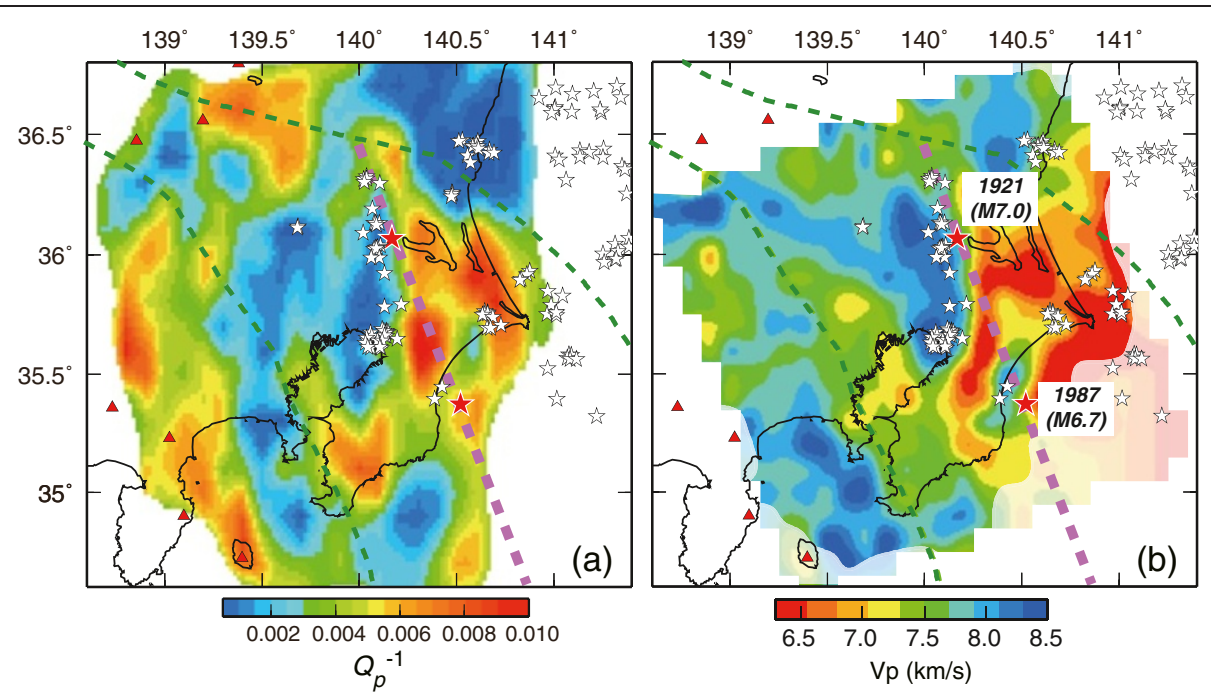

Figure 7 Seismic attenuation and velocity structure inside the Philippine Sea slab. (a) $Q_{p}^{-1}$ and (b) $P$-wave velocity along a curved surface located $10 \mathrm{~km}$ above the upper surface of the Pacific slab. White stars represent small repeating earthquakes that occurred on the Pacific slab. Other symbols are the same as in Figure 1.

being observed along the eastern part of lines A-C. Consequently, the mantle of the Philippine Sea slab is characterized by high attenuation and low velocity in eastern Kanto (line D) and by low attenuation and high velocity in western Kanto (line E). Such an E-W variation in attenuation is confirmed in Figure 2b, which shows that rays that propagate to eastern stations tend to have path-average $Q_{p}^{-1}$ higher than those that propagate to western stations.

\section{Discussion}

\section{High-attenuation areas in the lower crust of the continental plate}

The high-attenuation area that is laterally extensive at a depth of $20 \mathrm{~km}$ can be divided into a region located around active volcanoes in the western part of the study area and a region located in non-volcanic areas. As high attenuation observed in the volcanic areas in western Kanto is comparable to that observed in volcanic areas, for example, in northeastern Japan (Nakajima et al. 2013) and Mexico (Chen and Clayton 2009), it is probably caused by high temperatures and magmatic fluids. In contrast, high attenuation in the lower crust of the non-volcanic areas cannot be due to a high-temperature effect, as this area has the lowest heat flow values (e.g., Tanaka et al. 2004) and the deepest cutoff depth $(>25 \mathrm{~km}$ ) of crustal earthquakes in the Japanese Islands (Omuralieva et al. 2012).

A key observation to interpret these non-volcanic, highattenuation areas of the lower crust is that almost no seismicity occurs in regions characterized by high attenuation and low velocity (Figures 5 and 6). A plausible cause of the aseismic and high-attenuation lower crust is the localization of overpressured fluids with a fluid pressure to lithostatic pressure ratio of approximately 1 . Such high pore pressures may no longer sustain significant regional shear stresses, which promotes aseismic deformation and enhances high attenuation. The enrichment of slab-derived silica in the lower crust (e.g., Breeding and Ague 2002) may also promote aseismic deformation. Abundant fluids, supplied from the subducting Philippine Sea slab over geological time scales due to slab metamorphism, are likely to play important roles in the promotion of a large-scale aseismic deformation in the lower crust.

The high-attenuation area observed at the corner of the mantle wedge corresponds to an area of low velocity and moderate-to-high $\mathrm{Vp} / \mathrm{Vs}$ ratio, where serpentinization may occur (e.g., Kamiya and Kobayashi 2000; Matsubara et al. 2005). Assuming that high attenuation represents the serpentinized mantle, serpentinization is confined to a small region immediately below the continental Moho. Because seismic ruptures along the plate boundary can propagate to greater depths beyond the localized serpentinized mantle (e.g., Collings et al. 2012), comprehensive evaluations involving the slip deficit along the plate boundary and frictional properties of serpentine are required to conclude whether the serpentinized mantle wedge could act as a barrier to megathrust seismic ruptures.

\section{High-attenuation mantle of the subducting Philippine Sea slab}

The most notable observation in this study is the existence of the high-attenuation area in the Philippine Sea slab mantle beneath eastern Kanto (Figures 6a,b,c and 7a). Although high temperatures are considered as the dominant cause of high attenuation in the mantle (e.g., Faul and Jackson 2005), a thermal effect is considered unlikely for the origin of high attenuation within the subducting 
mantle. The high-attenuation mantle corresponds spatially to the proposed serpentinized slab mantle with low velocity (Figure 1b) and high Vp/Vs (Nakajima and Hasegawa 2010), and hence marked high attenuation is interpreted to be attributable to the serpentinized mantle with high water content, low viscosity (e.g., Hilairet et al. 2007), and small grain sizes (e.g., Mizukami and Wallis 2005). The wedge-shaped mantle of the Philippine Sea plate has been serpentinized prior to subduction (Kamimura et al. 2002), and serpentinization is considered to have been preserved after subduction because temperatures in the eastern portion of the Philippine Sea slab remain in the serpentine stability field (e.g., Iwamori 2000). Additional serpentinization has probably also occurred after subduction, given that fluids have been supplied by dehydration reactions occurring in the underlying Pacific slab. An important consequence of this interpretation is the enhancement of attenuation by serpentinization.

Small repeating earthquakes along the upper surface of the Pacific slab (white stars in Figure 7) (Uchida et al. 2009) occur in areas that are overlain by low-attenuation and high-velocity mantle of the Philippine Sea slab and are absent below the serpentinized slab mantle (Figure 7). The results of deformation experiments performed on serpentine show that its viscosity is significantly lower than that of the major non-metamorphic mantle-forming minerals; thus brittle failures are unlikely to occur (e.g., Moore et al. 1997; Hilairet et al. 2007). Observations in this study are consistent with the interpretation made by Hilairet et al. (2007) in that interplate earthquakes do not occur when the plate boundary is in contact with serpentinized mantle.

Two $M \sim 7$ earthquakes in the Philippine Sea slab (red stars in Figure 7) are interpreted to have occurred as a result of right-lateral deformation along the western boundary of the serpentinized mantle (Nakajima and Hasegawa 2010). The western boundary of the observed high-attenuation mantle coincides with that of the serpentinized mantle (Figure 7a), suggesting that these two earthquakes occurred at the sharp boundary between the high-attenuation mantle to the east and the lowattenuation mantle to the west. Although it is inconclusive as to whether the western boundary of the serpentinized mantle corresponds to the thermal limit of the stability field of serpentine or whether it is controlled by the distribution of fluids, frictional properties and pore fluid pressures may change abruptly across the boundary. These observations highlight the importance of heterogeneity in the subducting mantle for the facilitation of intermediate-depth earthquakes.

\section{Conclusions}

This study characterizes seismic attenuation structure and discusses spatial relations between seismic attenuation and seismic activity beneath Kanto, Japan. The attenuation model yields additional insights into seismogenesis in this tectonically complex region. The main conclusions are summarized as follows.

1. The lower continental crust above the Philippine Sea slab shows high attenuation and is almost aseismic. Ductile deformation is likely to be dominant, associated with overpressured fluids supplied from the underlying Philippine Sea slab.

2. The corner of the mantle wedge in the continental plate may be serpentinized, but the extent of serpentinization is limited to a small region below the Moho.

3. The serpentinized mantle of the Philippine Sea slab shows high attenuation as well as low velocity, which strongly suggests that serpentinization enhances attenuation in the seismic frequency band.

The attenuation model obtained in this study will provide a practical constraint on the evaluation of realistic strong motions at the surface, which is crucial for the assessment and management of seismic hazards in the Tokyo metropolitan area.

\section{Competing interests}

The author declares that he has no competing interests.

\section{Acknowledgments}

A. Hasegawa, I. Katayama, and K. Hirauchi are thanked for comments and discussions, and N. Uchida is thanked for providing data relating to small repeating earthquakes. Constructive and careful reviews by two anonymous reviewers improved the manuscript. This work used waveform data recorded at a nationwide seismograph network and arrival time data in the unified catalogue of the Japan Meteorological Agency. This work was supported by the Ministry of Education, Culture, Sports, Science, and Technology of Japan, under its Observation and Research Program for the Prediction of

Earthquakes and Volcanic Eruptions, and by JSPS KAKENHI Grant Number 24740300 .

Received: 9 December 2013 Accepted: 25 March 2014 Published: 16 April 2014

\section{References}

Breeding CM, Ague JJ (2002) Slab-derived fluids and quartz-vein formation in an accretionary prism. Otago Schist, New Zealand, Geology 30:499-502

Brune JN (1970) Tectonic stress and spectra of seismic shear waves from earthquakes. J Geophys Res 75:4997-5009

Chen T, Clayton RW (2009) Seismic attenuation structure in central Mexico: image of a focused high-attenuation zone in the mantle wedge. J Geophys Res 114:B07304. doi:10.1029/2008JB005964

Collings R, Lange D, Rietbrock A, Tilmann F, Natawidjaja D, Suwargadi B, Miller M, Saul J (2012) Structure and seismogenic properties of the Mentawai segment of the Sumatra subduction zone revealed by local earthquake travel time tomography. J Geophys Res 117:B01312. doi:10.1029/2011JB008469

Faul UH, Jackson I (2005) The seismological signature of temperature and grain size variations in the upper mantle. Earth Planet Sci Lett 234:119-134

Hasegawa A, Umino N, Takagi A (1978) Double-planed structure of the deep seismic zone in the northeastern Japan arc. Tectonophysics 47:43-58

Hilairet N, Reynard B, Wang Y, Daniel I, Merkel S, Nishiyama N, Petitgirard S (2007) High-pressure creep of serpentine, interseismic deformation, and initiation of subduction. Science 318:1910-1913

Hirose F, Nakajima J, Hasegawa A (2008) Three-dimensional velocity structure and configuration of the Philippine Sea slab beneath Kanto district, central Japan, 
estimated by double-difference tomography (in Japanese with English abstract). J Seismo Soc Jpn 60:123-138

Hori S (2006) Seismic activity associated with the subducting motion of the Philippine Sea plate beneath the Kanto district. Japan, Tectonophysics 417:85-100

Iwamori $\mathrm{H}$ (2000) Deep subduction of $\mathrm{H}_{2} \mathrm{O}$ ad deflection of volcanic chain towards backarc near triple junction due to lower temperature. Earth Planet Sci Lett 181:41-46

Jackson I, Fitz Gerald JD, Faul UH, Tan BH (2002) Grain-size sensitive seismic wave attenuation in polycrystalline olivine. J Geophys Res 107(B12):2360. doi:10.1029/2001JB001225

Kamimura A, Kasahara J, Shinohara M, Hino R, Shiobara H, Fujie G, Kanazawa T (2002) Crustal structure study at the Izu-Bonin subduction zone around $31^{\circ} \mathrm{N}$ : implications of serpentinized materials along the subduction plate boundary. Phys Earth Planet Inter 132:105-129

Kamiya S, Kobayashi Y (2000) Seismological evidence for the existence of serpentinized wedge mantle. Geophys Res Lett 27:819-822

Katsumata A (2010) Depth of the Moho discontinuity beneath the Japanese islands estimated by traveltime analysis. J Geophys Res 115:B04303. doi:10.1029/2008JB005864

Kimura H, Kasahara K, Igarashi T, Hirata N (2006) Repeating earthquake activities associated with the Philippine Sea plate subduction in the Kanto district, central Japan: a new plate configuration revealed by interpolate aseismic slips. Tectonophysics 417:101-118

Matsubara M, Hayashi H, Obara K, Kasahara K (2005) Low-velocity oceanic crust at the top of the Philippine Sea and Pacific plates beneath the Kanto region, central Japan, imaged by seismic tomography. J Geophys Res 110:B12304. doi:10.1029/2005JB003673

Mizukami T, Wallis SR (2005) Structural and petrological constraints on the tectonic evolution of the garnet-Iherzolite facies Higashi-akaishi peridotite body. Sanbagawa belt, SW Japan, Tectonics 24:TC6012. doi:10.1029/ 2004TC001733

Moore DE, Lockner DA, Shengli M, Summers R, Byerlee JD (1997) Strength of serpentinite gouges at elevated temperatures. J Geophys Res 102:14787-14801

Nakajima J, Hasegawa A (2007) Subduction of the Philippine Sea plate beneath southwestern Japan: slab geometry and its relationship arc magmatism. J Geophys Res 112:B08306. doi:10.1029/2006JB004770

Nakajima J, Hasegawa A (2010) Cause of M 7 intraslab earthquakes beneath the Tokyo metropolitan area: possible evidence for a vertical slab tear at the easternmost portion of the Philippine Sea slab. J Geophys Res 115:B04301. doi:10.1029/2009JB006863

Nakajima J, Hirose F, Hasegawa A (2009) Seismotectonics beneath the Tokyo metropolitan area: effect of slab-slab contact and overlap on seismicity. J Geophys Res 114:B08309. doi:10.1029/2008JB006101

Nakajima J, Hasegawa A, Hirose F (2011) Stress regime in the Philippine Sea slab beneath Kanto, Japan. Geophys Res Lett 38:L16318. doi:10.1029/ 2011GL048754

Nakajima J, Hada S, Hayami E, Uchida N, Hasegawa A, Yoshioka S, Matsuzawa T, Umino N (2013) Seismic attenuation beneath northeastern Japan: constraints on mantle dynamics and arc magmatism. J Geophys Res Solid Earth 118. doi:10.1002/2013JB010388

Nakamura R, Satake K, Toda S, Uetake T, Kamiya S (2006) Three-dimensional attenuation (Qs) structure beneath the Kanto district, Japan, as inferred from strong motion records. Geophys Res Lett 33:L21304. doi:10.1029/ 2006GL027352

Omuralieva AM, Hasegawa A, Matsuzawa T, Nakajima J, Okada T (2012) Lateral variation of the cutoff depth of shallow earthquakes beneath the Japanese Islands and its implications for seismogenesis. Tectonophysics 518-521:93-105

Rietbrock A (2001) P wave attenuation structure in the fault area of the 1995 Kobe earthquake. J Geophys Res 106:4141-4154

Sato H, Hirata N, Koketsu K, Okaya D, Abe S, Kobayashi R, Matsubara M, Iwasaki T, Ito T, Ikawa T, Kawanaka T, Kasahara K, Harder S (2005) Earthquake source fault beneath Tokyo. Science 309:462-464

Sekiguchi S (1991) Three-dimensional Q structure beneath the Kanto-Tokai district. Japan, Tectonophysics 195:83-104

Stachnik JC, Abers GA, Christensen DH (2004) Seismic attenuation and mantle wedge temperatures in the Alaska subduction zone. J Geophys Res 109: B10304. doi:10.1029/2004JB003018

Tanaka A, Yamano M, Yano Y, Sasada M (2004) Geothermal gradient and heat flow data in and around Japan (I): appraisal of heat flow from geotherma gradient data. Earth Planets Space 56:1191-1194
Uchida N, Nakajima J, Hasegawa A, Matsuzawa T (2009) What controls interplate coupling? evidence for abrupt change in coupling across a border between two overlying plates in the NE Japan subduction zone. Earth Planet Sci Lett 283:111-121

Uchida N, Matsuzawa T, Nakajima J, Hasegawa A (2010) Subduction of a wedge-shaped Philippine Sea plate beneath Kanto, central Japan, estimated from converted waves and small repeating earthquakes. J Geophys Res 115:B07309. doi:10.1029/2009JB006962

Wu F, Okaya D, Sato H, Hirata N (2007) Interaction between two subducting plates under Tokyo and its possible effects on seismic hazards. Geophys Res Lett 34:L18301. doi:10.1029/2007GL030763

Zhao D, Hasegawa A, Horiuchi S (1992) Tomographic imaging of P and S wave velocity structure beneath northeastern Japan. J Geophys Res 97:19909-19928

doi:10.1186/1880-5981-66-12

Cite this article as: Nakajima: Seismic attenuation beneath Kanto, Japan: evidence for high attenuation in the serpentinized subducting mantle. Earth, Planets and Space 2014 66:12.

\section{Submit your manuscript to a SpringerOpen ${ }^{\odot}$ journal and benefit from:}

- Convenient online submission

- Rigorous peer review

- Immediate publication on acceptance

- Open access: articles freely available online

High visibility within the field

- Retaining the copyright to your article

Submit your next manuscript at $\gg$ springeropen.com 